DOI: https://doi.org/10.11144/Javeriana.umed60-1.cand

\title{
Epidemiology of Candidemia at a University Hospital in Colombia, 2008-2014
}

\section{Epidemiología de los casos de candidemia en un hospital universitario en Colombia, 2008-2014}

Received: 21 May 2018 | Accepted: 06 August 2018

\author{
Julian Esteban BARAhona-Correa ${ }^{\mathrm{a}}$ \\ Pontificia Universidad Javeriana, Colombia \\ María Gabriela Calvo-Valderrama ${ }^{\mathrm{b}}$ \\ Pontificia Universidad Javeriana, Colombia \\ Diana Marcela Romero-Alvernia ${ }^{c}$ \\ Pontificia Universidad Javeriana, Colombia \\ Juliana Angulo-Mora ${ }^{\mathrm{d}}$ \\ Pontificia Universidad Javeriana, Colombia \\ Luisa Fernanda Alarcón-Figueroa ${ }^{\mathrm{e}}$ \\ Pontificia Universidad Javeriana, Colombia \\ María Nelcy Rodríguez-Malagón ${ }^{f}$ \\ Pontificia Universidad Javeriana, Colombia \\ Javier Ricardo Garzón-Herazog \\ Pontificia Universidad Javeriana, Colombia
}

a MD. School of Medicine, Pontificia Universidad Javeriana, Bogotá, Colombia. Grupo de Investigación en Enfermedades Infecciosas, Hospital Universitario San Ignacio, Pontificia Universidad Javeriana, Bogotá, Colombia.

b MD. School of Medicine, Pontificia Universidad Javeriana, Bogotá, Colombia.

c MD. School of Medicine, Pontificia Universidad Javeriana, Bogotá, Colombia.

d MD. School of Medicine, Pontificia Universidad Javeriana, Bogotá, Colombia.

e MD. School of Medicine, Pontificia Universidad Javeriana, Bogotá, Colombia.

f MSc. Director of the Department of Epidemiology and Biostatistics, School of Medicine, Pontificia Universidad Javeriana, Bogotá, Colombia.

g MD. Professor of the School of Medicine, Pontificia Universidad Javeriana, Bogotá, Colombia. Infectious Disease specialist, Hospital Universitario San Ignacio, Bogotá, Colombia. Grupo de Investigación en Enfermedades Infecciosas, Hospital Universitario San Ignacio, Pontificia Universidad Javeriana, Bogotá, Colombia.

\begin{abstract}
Introduction: Candida species are commensal yeasts of the human microbiota. However, due to several host's conditions, bloodstream infections may arise causing high morbimortality. Methods: Retrospective cross-sectional analytical study of positive blood cultures for Candida spp. between 2008-2014 at a university hospital in Bogota, Colombia. We evaluated clinical and microbiological characteristics prior to the first positive blood sample was obtained and determined associations with non-C. albicans (NCA) species infections. Results: We included 123 candidemia cases. C. albicans was the most frequently isolated species (42\%). However, NCA species as a group were observed more often. Over $70 \%$ of cases were managed at the ICU, with a median stay of 14 days. Several medical factors were frequently observed, however none appeared to be associated with NCA species candidemia. Resistance to at least one antifungal agent was observed in $29 \%$ of cases, although a reduced sample of susceptibility tests was available. Conclusions: Our results support a worldwide shift towards NCA candidemia. However, clinical features were not associated with NCA infections. The identification of risk factors and the improvement of prediction scores must be prioritized, in order to identify patients at high risk who may benefit of pre-emptive therapy.

Keywords

candida; candidemia; fungal drug resistance; epidemiology; risk factors.
\end{abstract}

MG, Romero-Alvernia DM, Angulo-Mora J, AlarcónFigueroa LF, Rodríguez-Malagón MN, Garzón-Herazo JR. Epidemiology of candidemia at a university hospital in Colombia, 2008-2014. Univ. Med. 2019;60(1). doi: https://doi.org/10.11144/ Javeria na.umed60-1.cand.

\section{RESUMEN}

Introducción: Candida spp. es una levadura comensal de la microbiota humana. Por características del hospedero, las infecciones del torrente 
Julian Esteban Barahona-Correa, María Gabriela Calvo-Valderrama, Diana Marcela Romero-Alvernia, et al.

sanguíneo pueden aparecer y causar una gran morbimortalidad. Métodos: Estudio restrospectivo transversal analítico de los cultivos positivos para Candida spp. entre 2008 y 2014 en un hospital universitario en Bogotá, Colombia. Se evaluaron las características clínicas y microbiológicas presentes previo a la toma de la primera muestra de sangre positiva y se determinaron asociaciones con infecciones por especies no C. albicans (NCA). Resultados: Se incluyeron 123 casos de candidemia. C. albicans fue la especie más aislada (42 \%). Sin embargo, las especies NCA como grupo fueron observadas más frecuentemente. Más del $70 \%$ de los casos presentaron manejo en la unidad de cuidado intensivo, con una mediana de estancia de 14 días previo a la primera muestra de sangre positiva. Se detectaron numerosas características médicas; sin embargo, ninguna estuvo asociada con candidemia por especies NCA. Se observó resistencia a por lo menos un antifúngico en el 29 \% de los casos, aunque en una muestra reducida de pruebas de sensibilidad. Conclusiones: Nuestros resultados sustentan el viraje mundial hacia la candidemia por especies NCA; pero no encontramos asociaciones clínicas en este grupo. Debe dársele prioridad a la identificación de factores de riesgo y a la optimización de los puntajes de predicción, que permitan identificar pacientes en riesgo que se beneficien de terapia preventiva.

Palabras clave

Candida; candidemia; farmacorresistencia fúngica; epidemiología; factores de riesgo.

\section{Introduction}

Candida spp. constitute the most common fungal agents causative of invasive disease in hospitalized patients (1). Candidemia is defined as the presence of the yeast in the bloodstream (2). It is considered the $4^{\text {th }}$ cause of septicemia in hospitalized patients in the USA (3) with a mortality rate of up to $60 \%$, thus surpassing mortality due to bacteremia $(4,5,6)$. It is associated with a longer hospital stay and a high economic burden to healthcare systems, which may sum up to USD 40.000 per patient $(4,7)$. Blood cultures are the mainstay diagnostic gold standard (2), however their performance appears to be low, with a false negative rate close to $50 \%$ (7). Candidemia incidence is rising worldwide, probably due to immunosuppressive therapies, organ transplantation, surgical interventions, and an aging population with multiple comorbidities $(7,8,9)$. Its main etiological agent is C. albicans, although a shift towards non-C. albicans (NCA) species with a reduced antifungal susceptibility is increasingly observed $(3,4,7)$, which makes candidemia a major public health issue. More than 90\% of candidemia cases present one of these species: C. albicans, C. glabrata, C. tropicalis, C. parapsilosis or C. krusei (10).

Incidence has been steady in highincome countries. Nevertheless, it has been rising in middle and low-income regions, such as Latin America (7). Several factors have been associated to candidemia, such as malignancies, diabetes, kidney disease, neutropenia, pancreatitis, Human Immunodeficiency Virus (HIV) infection, major surgery, mechanical ventilation, parenteral nutrition, chemotherapy, corticosteroids, and immunosuppression (11). A number of predictive rules and scores are available, which may identify high risk patients that may benefit of preemptive therapy $(11,12,13,14,15)$. Since the 90 s (7), a worrisome shift towards NCA candidemia is increasingly observed worldwide. Thus, we aimed to describe the epidemiologic profile of candidemia cases at our institution and to assess clinical associations with the development of NCA species candidemia.

\section{Methods}

\section{Patient enrollment and data collection}

We conducted a retrospective cross-sectional analytical study using the registry of positive blood cultures between January 2008 and January 2014 at a University Hospital in Bogota, Colombia. Candidemia cases managed at our university hospital and confirmed by a positive blood culture were included. Candidemia cases without microbiologic confirmation were excluded. When susceptibility tests were available, antifungal resistance profile was assessed. 
Study variables

Based on previously reported risk factors (16), clinical and microbiologic characteristics were included: Candida species, susceptibility profile, patient's age, gender, and clinical characteristics present prior to obtaining the first positive sample. The clinical characteristics included were diabetes, hematologic or solid malignancies, chemotherapy, kidney disease (acute or chronic), HIV, corticosteroids, biologic therapy, neutropenia, days of stay at the Intensive Care Unit (ICU), parenteral nutrition, mechanical ventilation, surgical intervention, pancreatitis and prior use of broad spectrum antibiotic or antifungal therapy.

\section{Statistical analysis}

Categorical variables were expressed as absolute and relative frequencies, whereas continuous variables were expressed as medians and interquartile ranges. Due to the study design, to establish associations and to measure their magnitude, contingency tables were determined and indirect relative risks with their confidence intervals were determined. To perform analysis, Stata (v.14) for Windows was used. The study was approved by our institution's Ethics and Research Committee.

\section{Results}

One-hundred twenty-three candidemia cases were obtained, out of which $53.7 \%$ were present in women. Table 1 presents the sample's demographic and clinical characteristics. A median age of 55 years (IQR 34-70 years) was observed for the general sample. Most of the cases were present in patients between 15 and 60 years (57\%), whereas less than $5 \%$ were detected in patients younger than 1 year.
Table 1

Demographic and clinical characteristics by isolated species

\begin{tabular}{|c|c|c|c|c|}
\hline Variable & \begin{tabular}{|l|} 
Total \\
$\%$ (n) \\
$n=123$
\end{tabular} & \begin{tabular}{|l|} 
C. albicans \\
$\%$ (n) \\
$\mathrm{n}=52$
\end{tabular} & $\begin{array}{l}\mathrm{NCA} \\
\%(\mathrm{n}) \\
\mathrm{n}=71\end{array}$ & Indirect Relative Risk \\
\hline Median age (years) & 55 & 53.5 & 55 & - \\
\hline [IQR] & [34-70] & {$[38,2-70]$} & [29-70] & \\
\hline Age subgroups & & & & NA \\
\hline $\begin{array}{l}0-14 \text { years } \\
\leq 1 \text { years }\end{array}$ & $\begin{array}{l}9(11) \\
4(5)\end{array}$ & $\begin{array}{l}18(2) \\
0(0)\end{array}$ & $\begin{array}{l}82(9) \\
7(5)\end{array}$ & - \\
\hline $15-60$ years & $57(70)$ & $44(31)$ & $56(39)$ & - \\
\hline$>60$ years & $34(42)$ & $45(19)$ & $55(23)$ & - \\
\hline Male patients & $46(57)$ & $52(27)$ & $42(30)$ & $1.45(0.67-3.23)$ \\
\hline HIV & $6(8)$ & $4(2)$ & $8(6)$ & $0.43(0.04-2.57)$ \\
\hline Corticosteroids & $36(44)$ & $35(18)$ & $37(26)$ & $0.92(0.4-2.06)$ \\
\hline Biologic therapy & $4(5)$ & $10(5)$ & $0(0)$ & NA \\
\hline Hematologic malignancy & $21(26)$ & $19(10)$ & $22(16)$ & $0.82(0.29-2.15)$ \\
\hline Solid malignancy & $20(25)$ & $25(13)$ & $17(12)$ & $1.64(0.61-4.37)$ \\
\hline Chemotherapy & $24(29)$ & $19(10)$ & $27(19)$ & $0.65(0.24-1.67)$ \\
\hline Diabetes & $18(22)$ & $17(9)$ & $18(13)$ & $0.93(0.32-2.61)$ \\
\hline Kidney failure & $43(53)$ & $40(21)$ & $45(32)$ & $0.83(0.37-1.81)$ \\
\hline Neutropenia & $24(29)$ & $17(9)$ & $28(20)$ & $0.53(0.19-1.38)$ \\
\hline ICU stay & $71(88)$ & $71(37)$ & $72(51)$ & $0.97(0.41-2.32)$ \\
\hline Median stay (days) & 14 & 14 & 14 & - \\
\hline [IQR] & [6-21] & {$[4-20.5]$} & [6-21] & \\
\hline Broad spectrum antibiotics & $99(122)$ & $100(52)$ & $99(70)$ & NA \\
\hline Parenteral nutrition & $41(51)$ & $38(20)$ & $44(31)$ & $0.81(0.36-1.78)$ \\
\hline Mechanical ventilation & $64(79)$ & $56(29)$ & $70(50)$ & $0.53(0.23-1.19)$ \\
\hline Surgical intervention & $80(99)$ & $77(40)$ & $83(59)$ & $0.68(0.25-1.84)$ \\
\hline Antifungal therapy & $21(26)$ & $15(8)$ & $25(18)$ & $0.53(0.18-1.45)$ \\
\hline Pancreatitis & $4(5)$ & $4(2)$ & $4(3)$ & $0.91(0.07-8.23)$ \\
\hline Total & $100(123)$ & $42.3(52)$ & $57.7(71)$ & \\
\hline \multicolumn{5}{|c|}{$\begin{array}{l}\text { IQR: Inter-quartile range; NCA: Non-Candida } \\
\text { albicans species; HIV: Human Immunodeficiency } \\
\text { Virus; ICU: Intensive Care Unit; NA: }\end{array}$} \\
\hline
\end{tabular}

Regarding clinical characteristics prior to obtaining the first positive blood sample, most patients received broad spectrum antibiotic therapy (99\%). Further, previous surgical intervention and mechanical ventilation were rather common, being present in $80 \%$ and $64 \%$ of cases, respectively. Over $70 \%$ of patients were managed at the ICU, with a median of 14 days prior to obtaining a positive blood sample. Over a third of cases presented kidney disease, received parenteral nutrition or corticosteroids. Interestingly, up to one quarter of patients received antifungal therapy, chemotherapy, presented neutropenia, or had diabetes. Less than $10 \%$ of patients were HIV positive or presented pancreatitis. Up to $40 \%$ of patients presented a medical history of either hematologic or solid malignancy. No differences 
Julian Esteban Barahona-Correa, María Gabriela Calvo-Valderrama, Diana Marcela Romero-Alvernia, et al.

were observed between C. albicans and NCA species cases.

As shown in Table 2, in patients with malignancies, NCA species were more frequently isolated (55\%). C. tropicalis (20\%), C. parapsilosis $(12 \%)$ and C. krusei (8\%) were the most often observed species.

\section{Table 2}

Distribution (\%) of Candida species by malignancy type

\begin{tabular}{|l|l|l|l|l|l|l|l|}
\hline Species & Total & $\begin{array}{l}\text { Head and } \\
\text { Neck }\end{array}$ & GI & Lung & GU & Hematologic & Other \\
\hline C. albicans & $23(45)$ & 3 & 5 & 1 & 2 & 10 & 2 \\
\hline NCA & $28(55)$ & & & & & & \\
\hline C. tropicalis & $\begin{array}{l}10 \\
(19.7)\end{array}$ & 1 & 1 & - & 1 & 7 & - \\
\hline C. parapsilosis & $6(11.8)$ & 1 & 1 & - & 1 & 2 & 1 \\
\hline C. krusei & $4(7.8)$ & - & 1 & - & - & 3 & - \\
\hline C. glabrata & $2(3.9)$ & 2 & - & - & - & - & - \\
\hline C. guillermondi & $3(5.9)$ & - & 1 & - & - & 2 & - \\
\hline C. inconspicua & $2(3.9)$ & 1 & - & - & - & 1 & - \\
\hline C. lusitaniae & $1(2)$ & - & - & - & - & 1 & - \\
\hline Total & $51(100)$ & $8(31)$ & $9(18)$ & $1(2)$ & $4(8)$ & $26(51)$ & $3(6)$ \\
\hline
\end{tabular}

GI: Gastrointestinal; GU: Genitourinary.

The most frequent species was C. albicans (42\%). As a group, NCA species were more often observed (58\% vs $42 \%)$. Susceptibility profiles were available for 21 cases (17\%) and up to $29 \%$ of cases were resistant to at least one antifungal agent (Table 3).

Table 3

Susceptibility profile (\%)

\begin{tabular}{|l|l|l|l|l|l|}
\hline & Total & Multi-sensible & Fluconazole $^{*}$ & Itraconazole & Voriconazole $^{*}$ \\
\hline C. albicans & $13(62)$ & 10 & 3 & - & 2 \\
\hline NAC & $8(38)$ & - & - & - & - \\
\hline C. glabrata & $1(5)$ & 1 & - & - & - \\
\hline C. tropicalis & $3(14)$ & 2 & - & - & 1 \\
\hline C. parapsilosis & $3(14)$ & 2 & - & 1 & - \\
\hline C. krusei & $1(5)$ & - & 1 & - & - \\
\hline Total & $21(100)$ & $15(71)$ & $3(14)$ & $1(5)$ & $2(10)$ \\
\hline
\end{tabular}

* Two C. albicans isolates were resistant to both fluconazole and voriconazole.

\section{Discussion}

Although the most frequently isolated species was C. albicans, a shift towards NCA species was detected when species were analyzed as a group. Several medical factors were frequently observed in candidemia cases, however none of them appeared to be associated with NCA species candidemia. The median stay in the ICU prior to a positive blood sample was 14 days.

Candida species isolation may be analyzed from two viewpoints. On the one hand, when single species isolations are analyzed, C. albicans is the most frequently isolated species $(17,18,19,20,21,22,23,24,25)$. On the other hand, when C. albicans and NCA species are compared, the latter reveals a clear dominance worldwide $(17,18,26,27,28,29,30)$. However, since the 90s, a shift towards NCA candidemia is increasingly observed (7). Previous epidemiological data in our country $(6,9,27,31,32)$ reported a high frequency of $\mathrm{C}$. parapsilosis and C. tropicalis.

Several risk factors for candidemia have been reported and were included in our study (16). Previous descriptions showed a higher frequency of candidemia in extreme of ages (i.e., younger than one year or older than 65 years) $(7,24)$, whereas our data present a higher frequency between 15- and 60-yearold patients. Regarding ICU stay, a previous Colombian study in non-neutropenic patients reported clinical risk factors associated with candidemia, namely a hospital stay over 25 days, previous use of meropenem, abdominal surgery and hemodialysis (33). No differences in mortality rates were observed when compared to controls. In addition, Cortés et al. (6) reported that most patients presented a prolonged ICU stay with a mean of 29 days. However, we must point out that the applied methodology differs from ours, as the authors evaluated the whole ICU stay whereas we assessed ICU stay up to obtaining the first positive sample, with a median of 14 days. This difference is of increasing relevance as it may be useful for future studies on pre-emptive therapy. Malignancies have been strongly associated with candidemia development $(17,21,23,26,27,34,35)$. In Latin America, Quindos et al. (7) supported this finding and reported a high frequency of $\mathrm{C}$. tropicalis isolation in these patients, particularly in Brazil and Colombia, similar to our findings. Noteworthy, in our study, C. krusei was rather frequent among this population, which may 
be related to a frequent use of fluconazole in oncology wards that may select this species (25). Further, several studies have reported that more than $30 \%$ of cases present prior use of antibiotics, surgical interventions, corticosteroids, mechanical ventilation or parenteral nutrition $(18,21,30)$. Noteworthy, our findings revealed a higher use of antibiotics and surgical interventions. Renal failure, chemotherapy, neutropenia or prior antifungal therapy are described in fewer studies $(25,36,37,38)$. Regarding HIV status, an Australian study (34) reported less than $1 \%$ of patients positive to HIV, in contrast to Kreusch et al. (39) in South Africa, who reported up to 20\%, which is probably due to a higher local prevalence of HIV infection (40). Our findings appear to be located in between, although every HIV positive patient had one or more additional risk factors for candidemia. Despite none of the assessed clinical features suggested an association with NCA species candidemia, a previous study in Taiwan described a higher frequency of neutropenia in patients with NCA species candidemia and a lower occurrence of candiduria and ICU stay, when compared to C. albicans candidemia (18).

A reduced sample of susceptibility tests was available. Most isolations were multi-sensible, although nearly $30 \%$ presented resistance to at least one antifungal agent, including one $\mathrm{C}$. krusei isolate resistant to fluconazole, which is considered natural resistance. No resistance to amphotericin or echinocandins was observed. Despite a rather small sample, a high frequency of resistant isolates was observed. However, we do not rule out biased results, as available susceptibility tests may have been requested on a 'no response to first-line antifungal therapy' basis or in suspected resistance due to previous antifungal therapy. A local epidemiological study in our country (6) reported fluconazole resistance in up to $3 \%$ of isolations using the cut-off points of Clinical and Laboratory Standards Institute (CLSI) 2008, which increased to 20\% using CLSI 2012 cut-off points. Similar results were concluded in a regional study with data from Colombia, Ecuador and Venezuela, which reported a $7 \%$ resistance to fluconazole (41).
Worldwide studies have reported susceptibility to fluconazole in more than $90 \%$ of isolations $(22,42,43)$.

Several clinical factors included in our study have been suggested as risk factors for candidemia development, although none was associated with an increased risk for NCA species infections. Due to the observed high frequency of prior antibiotic use and surgical interventions, we hypothesize that the alteration of the microbiota in the gastrointestinal tract may generate intestinal dysbiosis that allows fungal structures, such as Candida species, to thrive freely, colonize and ultimately disseminate $(44,45)$. Immunocompromised patients (e.g., diabetes, malignancies, immunosuppressed, renal failure) may be more prone to yeast invasive infections $(45,46)$. New factors associated with the onset of candidemia, such as colonization by carbapenemase-producing Klebsiella pneumoniae and Clostridium difficile infections may support this hypothesis $(47,48,49)$.

We acknowledge some drawbacks of our study. First, the small sample size may limit our results. Second, our institution is a nationalrenowned third-level hospital in which complex patients are usually treated, thus our data may reflect a selection bias. Third, due to the retrospective cross-sectional nature of our study, the identification of associations is limited, which may explain the absence of associations with clinical features. This fact supports the importance of case-control, multicenter and prospective studies that may allow the identification of relevant characteristics associated with NCA species infection. Although blood cultures are the current gold standard for candidemia diagnosis, their performance appears to be low. New diagnostic tests may improve diagnostic performance, particularly in invasive candidiasis cases $(50,51)$.

Finally, new emerging Candida species with an antimicrobial resistant phenotype have been identified. One of such species is C. auris, which has been reported in over a dozen of countries, including our institution $(33,52,53,54)$. Although this species was not observed in our study, an increasing awareness 
Julian Esteban Barahona-Correa, María Gabriela Calvo-Valderrama, Diana Marcela Romero-Alvernia, et al.

is warranted. C. auris should be suspected when species identification cannot be obtained or certain Candida species are identified (e.g., Rhodotorula glutinis, C. famata, C. catenulate, C. haemulonii, C. sake), particularly when standard biochemical identification kits are used (55).

\section{Conclusion}

Candida spp. is among the top five causes of bloodstream invasive infection worldwide, with a mortality rate of up to $60 \%$. Our results support a shift towards NCA species infections, although no clinical variables were particularly associated. The identification of risk factors, earlier and timely diagnostic approaches and the improvement of prediction scores must be prioritized, in order to identify patients at high risk who may benefit from pre-emptive therapy.

\section{Funding}

The present work did not receive any funding.

\section{Acknowledgements}

We thank the Clinical Laboratory and the Hospital Archive for their unconditional help to develop this project. Also Dr. Andrés Laserna, for his valuable comments on the manuscript.

\section{References}

1. Falagas ME, Roussos N, Vardakas KZ. Relative frequency of albicans and the various non-albicans Candida spp. among candidemia isolates from inpatients in various parts of the world: A systematic review. Int J Infect Dis. 2010;14(11):e954-66.

2. Colombo AL, Cortes JA, Zurita J, et al. Recommendations for the diagnosis of candidemia in Latin America. Rev Iberoam Micol. 2013;30(3):150-7.
3. Mikulska M, Del Bono V, Ratto S, Viscoli C. Occurrence, presentation and treatment of candidemia. Expert Rev Clin Immunol. 2012;8(8):755-65.

4. Arendrup MC. Epidemiology of invasive candidiasis. Curr Opin Crit Care. 2010;16:445-52.

5. Zhang X-BB, Yu S-JJ, Yu J-XX, et al. Retrospective analysis of epidemiology and prognostic factors for candidemia at a hospital in China, 2000-2009. Jpn J Infect Dis. 2012;65(6):510-5.

6. Cortés JA, Reyes P, Gómez CH, et al. Clinical and epidemiological characteristics and risk factors for mortality in patients with candidemia in hospitals from Bogotá, Colombia. Brazilian J Infect Dis. 2014;18(6):631-7.

7. Quindós G. Epidemiology of candidaemia and invasive candidiasis: A changing face. Rev Iberoam Micol. 2014;31(1):42-8.

8. Botero MC, Puentes-Herrera M, Cortés JA. [Lipid formulations of amphotericin]. Rev Chilena Infectol. 2014;31(5):518-27.

9. Cortés JA, Reyes P, Gómez C, Buitrago G, Leal AL. Fungal bloodstream infections in tertiary care hospitals in Colombia. Rev Iberoam Micol. 2011;28(2):74-8.

10. Guinea J. Global trends in the distribution of Candida species causing candidemia. Clin Microbiol Infect. 2014;20(Suppl 6):5-10.

11. Antinori S, Milazzo L, Sollima S, Galli M, Corbellino M. Candidemia and invasive candidiasis in adults: A narrative review. Eur J Intern Med. 2016;34:21-8.

12. Hermsen ED, Zapapas MK, Maiefski $\mathrm{M}$, et al. Validation and comparison of clinical prediction rules for invasive candidiasis in intensive care unit patients: A 
matched case-control study. Crit Care. 2011;15(4):R198.

13. Ostrosky-Zeichner L, Pappas PG, Shoham S, et al. Improvement of a clinical prediction rule for clinical trials on prophylaxis for invasive candidiasis in the intensive care unit. Mycoses. 2011;54(1):46-51.

14. León C, Ruiz-Santana S, Saavedra $\mathrm{P}$, et al. A bedside scoring system ("Candida score") for early antifungal treatment in nonneutropenic critically ill patients with Candida colonization. Crit Care Med. 2006;34(3):730-7.

15. Eggimann P, Garbino J, Pittet D. Epidemiology of Candida species infections in critically ill nonimmunosuppressed patients. Lancet Infect Dis. 2003;3(11):685-702.

16. Pappas PG, Kauffman CA, Andes $\mathrm{D}$, et al. Clinical practice guidelines for the management of candidiasis: 2009 update by the Infectious Diseases Society of America. Clin Infect Dis. 2009;48:503-35.

17. Chen CY, Huang SY, Tsay $\mathrm{W}$, et al. Clinical characteristics of candidaemia in adults with haematological malignancy, and antimicrobial susceptibilities of the isolates at a medical centre in Taiwan, 2001-2010. Int J Antimicrob Agents. 2012;40:533-8.

18. Chi H-W, Yang Y-S, Shang S$\mathrm{T}$, et al. Candida albicans versus non-albicans bloodstream infections: The comparison of risk factors and outcome. J Microbiol Immunol Infect. 2011;44(5):369-75.

19. Vincent J-L, Rello J, Marshall $\mathrm{J}$, et al. International study of the prevalence and outcomes of infection in intensive care units. JAMA. 2009;302:2323-9.

20. Ruan S-YY, Hsueh P-RR. Invasive candidiasis: An overview from Taiwan. J Formos Med Assoc. 2009;108(6):443-51.

21. Pfaller M, Neofutos D, Diekema $\mathrm{D}$, et al. Epidemiology and outcomes of candidemia in 3648 patients: data from the Prospective Antifungal Therapy (PATH Alliance $\left.{ }^{\circledR}\right)$ registry, 2004-2008. Diagn Microbiol Infect Dis. 2012;74(4):323-31.

22. Pfaller MA, Diekema DJ, Jones $\mathrm{RN}$, et al. International surveillance of bloodstream infections due to Candida species: frequency of occurrence and in vitro susceptibilities to fluconazole, ravuconazole, and voriconazole of isolates collected from 1997 through 1999 in the SENTRY antimicrobial surv. J Clin Microbiol. 2001;39(9):3254-9.

23. Erdem I, Oguzoglu N, Ozturk Engin $\mathrm{D}$, et al. Incidence, etiology and risk factors associated with mortality of nosocomial candidemia in a tertiary care hospital in Istanbul, Turkey. Med Princ Pract. 2010;19:463-7.

24. Nucci M, ThompsonMoya L, Guzman-Blanco M, et al. Recommendations for the management of candidemia in adults in Latin America. Rev Iberoam Micol. 2013;30(3):179-88.

25. Ben-Ami R, Olshtain-Pops K, Krieger M, et al. Antibiotic exposure as a risk factor for fluconazole-resistant Candida bloodstream infection. Antimicrob Agents Chemother. 2012;56(5):2518-23.

26. Zilberberg MD, Shorr AF, Kollef $\mathrm{MH}$. Growth and geographic variation in hospitalizations with resistant infections, United States, 2000-2005. Emerg Infect Dis. 2008;14:1756-8.

27. Nucci M, Queiroz-Telles F, Alvarado-Matute $\mathrm{T}$, et al. Epidemiology of Candidemia in Latin 
Julian Esteban Barahona-Correa, María Gabriela Calvo-Valderrama, Diana Marcela Romero-Alvernia, et al.

America: A Laboratory-Based Survey. PLoS One. 2013;8.

28. Adhikary R, Joshi S. Species distribution and anti-fungal susceptibility of Candidaemia at a multi super-specialty center in Southern India. Indian J Med Microbiol. 29:309-11.

29. Jutiamornlerd N, Chusri S, Sirsipaitoon P. Epidemiology of candidemia in Songklanagarind hospital. J Med Assoc Thail. 2011;94:927-32.

30. Boonyasiri A, Jearanaisilavong J, Assanasen S. Candidemia in Siriraj Hospital: epidemiology and factors associated with mortality. J Med Assoc Thai. 2013;96 Suppl 2(Suppl 2):S91-7.

31. Diazgranados CA, Martínez A, Deaza C, Valderrama S. An outbreak of Candida spp. bloodstream infection in a tertiary care center in Bogotá, Colombia. Braz J Infect Dis. 2008;12(5):390-4.

32. Ortiz Ruiz G, Osorio J, Valderrama S, et al. Risk factors for candidemia in non-neutropenic critical patients in Colombia. Med intensiva. 2016;40(3):139-44.

33. Rodríguez-Morales AJ, SabogalRomán JA, Álvarez-Moreno CA. What has been researched about MDRCandida auris? A bibliometric analysis on the "new kid on the block" in hospital-associated infections. J Infect Public Health. 2017;11(2):295-6.

34. Chen S, Slavin M, Nguyen $Q$, et al. Active surveillance for candidemia, Australia. Emerg Infect Dis. 2006;12:1508-16.

35. Asmundsdottir LR, Erlendsdottir $\mathrm{H}$, Gottfredsson M. Nationwide study of candidemia, antifungal use, and antifungal drug resistance in Iceland, 2000 to 2011. J Clin Microbiol. 2013;51:841-8.
36. Yapar N, Pullukcu H, AvkanOguz V, et al. Evaluation of species distribution and risk factors of candidemia: a multicenter case-control study. Med Mycol. 2011;49:26-31.

37. Yapar N. Epidemiology and risk factors for invasive candidiasis. Ther Clin Risk Manag. 2014;10:95-105.

38. Tortorano AM, Peman J, Bernhardt $\mathrm{H}$, et al. Epidemiology of candidaemia in Europe: results of 28-month European Confederation of Medical Mycology (ECMM) hospital-based surveillance study. Eur J Clin Microbiol Infect Dis. 2004;23(4):317-22.

39. Kreusch A, Karstaedt AS. Candidemia among adults in Soweto, South Africa, 1990-2007. Int J Infect Dis. $2013 ; 17$.

40. Deeks SG, Overbaugh J, Phillips A, Buchbinder S. HIV infection. Nat Rev Dis Prim. 2015;15035.

41. de Bedout C, Ayabaca J, Vega R, et al. Evaluation of Candida species' susceptibility to fluconazole with the disk diffusion method. Biomedica. 2003;23(1):31-7.

42. Chen P-LL, Lo H-JJ, Wu CJJ, et al. Species distribution and antifungal susceptibility of blood Candida isolates at a tertiary hospital in southern Taiwan, 1999-2006. Mycoses. 2011;54(4):17-23.

43. Pfaller MA, Diekema DJ. Twelve years of fluconazole in clinical practice: Global trends in species distribution and fluconazole susceptibility of bloodstream isolates of Candida. Clin Microbiol Infect. 2004;10 Suppl 1:11-23.

44. Underhill DM, Iliev ID. The mycobiota: interactions between commensal fungi and the host immune system. Nat Rev Immunol. 2014;14(6):405-16. 
45. Martínez-Álvarez JA, Pérez-García LA, Flores-Carreón A, Mora-Montes HM. The immune response against Candida spp. and Sporothrix schenckii. Rev Iberoam Micol. 2013;31(1):1-5.

46. Lionakis MS, Kontoyiannis DP. Glucocorticoids and invasive fungal infections. Vol. 362, Lancet. 2003. p. 1828-38.

47. Guastalegname M, Russo A, Falcone M, Giuliano S, Venditti M. Candidemia subsequent to severe infection due to Clostridium difficile: is there a link? Clin Infect Dis. 2013;57(5):772-4.

48. Papadimitriou-Olivgeris $\mathrm{M}$, Spiliopoulou A, Fligou F, et al. Association of KPC-producing Klebsiella pneumoniae colonization or infection with Candida isolation and selection of non-albicans species. Diagn Microbiol Infect Dis. 2014;80(3):227-32.

49. Russo A, Falcone M, Fantoni M, et al. Risk factors and clinical outcomes of candidaemia in patients treated for Clostridium difficile infection. Clin Microbiol Infect. 2015;21(5):493.e1-4.

50. Clancy CJ, Nguyen $\mathrm{MH}$. Finding the "missing 50\%" of invasive candidiasis: how nonculture diagnostics will improve understanding of disease spectrum and transform patient care. Clin Infect Dis. 2013;56(9):1284-92.

51. Haas M, Grenouillet F, Loubersac $\mathrm{S}$, et al. Identification of cryptic Candida species by MALDI-TOF mass spectrometry, not all MALDITOF systems are the same: focus on the C. parapsilosis species complex. Diagn Microbiol Infect Dis. 2016;86(4):385-6.

52. Tsay S, Kallen A, Jackson BR, Chiller TM, Vallabhaneni S. Approach to the investigation and management of patients with Candida auris, an emerging multidrug-resistant yeast. Clin Infect Dis. 2018;66(2):306-11.

53. Parra-Giraldo CM, Valderrama SL, Cortes-Fraile G, et al. First report of sporadic cases of Candida auris in Colombia. Int J Infect Dis. 2018;69:63-7.

54. Morales-López SE, Parra-Giraldo CM, Ceballos-Garzón A, et al. Invasive infections with multidrug-resistant yeast Candida auris, Colombia. Emerg Infect Dis. 2017;23(1):162-4.

55. Mizusawa M, Miller H, Green $\mathrm{R}$, et al. Can multidrug-resistant Candida auris be reliably identified in clinical microbiology laboratories? J Clin Microbiol. 2017;55(2):638-40. 